\title{
Developing Algebraic and Geometric Understanding of Stereology in Biological Contexts
}

\author{
Ann S. O’Neil ${ }^{1}$, Rebecca M. Krall ${ }^{2}$, Maddie Sanden ${ }^{1}$, and Robin L. Cooper ${ }^{1}$ \\ ${ }^{1} 675$ Rose St., Department of Biology, University of Kentucky, Lexington KY 40506-0225 USA \\ ${ }^{2}$ Department of STEM Education, 105 Taylor Education Bldg, 597 S. Upper St, University of \\ Kentucky, Lexington KY 40406-0001, USA
}

(asc1029@gmail.com; rebecca.krall@uky.edu; maddie.sanden@gmail.com;

\section{RLCOOP1@uky.edu)}

\begin{abstract}
Next Generation Science Standards and college level STEM coursework emphasize the application of science, technology, engineering design, and mathematics to promote reasoning and problem-solving skills applied in formulating potential solutions for real-world problems. One such problem relevant to students in grades 6-12 and at the introductory college level is successfully deciphering structures they attempt to view with microscopes and telescopes. Such experiences can become a frustrating practice because of the limited knowledge of stereology. The goal of this module is to apply algebraic and geometric principles to elucidate stereology as it applies to making sense of 3-D images and 2-D cross-section images derived from the projection of 3-D images. The module builds student understanding through a series of visual demonstrations using basic principles used in imaging of structures with short didactic presentations to scaffold learning. Students construct physical models to demonstrate stereology and explain it in the context of microscopic images, and computer tomography (CT). Integrating algebra and geometry in relation to stereological phenomena is of importance in developing appreciation of mathematical application in scientific topics, a deeper understanding of technology applications in science, and more specifically in understanding the application of stereology in scientific imaging.
\end{abstract}

Keywords: Stereology, imaging, anatomy

Link to Original Poster File: https://doi.org/10.37590/able.v41.poster77

\section{Introduction}

Using models to explore and construct scientific explanations promotes metacognitive thinking, communication skills, and fosters the development and refinement of mental models in learning science (Gilbert et al. 2000; Seel, 2017). Models represent knowledge about specific phenomenon that can be used to answer practical and hypothetical experimental questions without performing an experiment (Seel, 1991). Development and then manipulation of physical models in sensemaking discussions can scaffold construction and refinement of mental models (Mayer, 1989; McNeill \& Krajcik, 2008; Lane, et al., 2008).

Model-based learning also is effective in supporting learners in forming mental models as they make sense of natural phenomena and complex scientific processes (McNeill \& Krajcik, 2008;
Schwartz et al., 2009; Seel, 2017). The use of physical models with guided inquiry supports the development of conceptual understanding and making connections across concepts (Coll et al., 2005; Schwartz et al., 2009; Ucar \& Trundle, 2011). Using models students and teachers can define components of complex biological problems and progress through increasingly complex objectives in a logical, stepwise progression leading to application of new knowledge to find possible solutions to real-world problems (Seel, 2017).

The modules herein support learning of stereology through inquiry and problem-based experiences. Students build physical models with readily available, inexpensive materials that make the abstract, complex concept of stereology concrete and accessible. They take stereological measurements to calculate a theoretical area or volume of objects, such as a triangle or triangular prism. Once they observe the actual 3-D 
object, students can then determine the potential error in estimations of area or volume from modeling with 2-D images in comparison to a true area or volume. The models also provide concrete, physical illustrations to aid in meaning-making discussions about stereology and how mathematical modeling and technology can be used to create reliable estimates of 3-D objects that would otherwise be invisible to the human eye.

Freeware, modeling software also can be used to animate objects for viewing in their 3-D and 2D forms. Software, such as SketchUp (https:// www.sketchup.com/) uses computational interaction and computer design to illustrate various points of view. This allows students to observe and discuss forms while providing a rapid means of altering structures and rotating them in 3-D space with no cost of supplies. Using both physical and computer designed models also offers a variety of tools and orientations to meet diverse student learning needs.

We present two modules. This first one is fitting for middle or high school level algebra, geometry and life science classes. And the second is targeted for high school and college level courses.
gThe second part is fitting for advanced algebra, eometry and calculus-based math classes and integrated with biology or anatomy and physiology courses which deal with organelles and physiological function in relation to cellular structure. Distance of objects with respect to each other as well as the shape of the objects is a focus in science. We see some objects in a 2$\mathrm{D}$ plane in snapshots such as in tissue, on a microscope slide, or an X-ray; however, if the objects are rotated to a viewer, a more complete 3-D image can be constructed.

Cell structure and general anatomical measures are a focus of life science concepts outlined in the NGSS (NGSS Lead States, 2013). Application of knowledge to real life problems in authentic scientific inquiry with active learning process along with construction of various types of models is a focus for the NGSS within the USA. In addition, applying practices from multiple disciplines and crosscutting concepts that integrate algebra and geometry in relation to stereological issues is of importance in developing an appreciation of mathematical application to biological topics. 


\section{Objectives}

\section{Student Outline}

Students will learn:

- how cross sections create a 3-D pattern of an object.

- how to create or work with models (2-D \& 3-D models).

- how to use of computer software for modeling.

- to describe stereology as reconstructing 3-D objects from 2-D cross-sectional slices as demonstrated in these activities.

- to be able to imagine possible shapes of a 3-D object when looking at a 2-D slice of tissue.

- to attend to the orientation of a small object embedded within a cross-section when interpreting the object's true shape.

- that it is not always possible to interpret the true structure of a 3-D object from a few serial cross-sections.

- sources of error when estimating the measurement of a 3-D object from 2-D planes.

- how to estimate an error and correct it in a measurement

\section{Introduction}

Thousands of years ago, the Chinese people used a unique form of storytelling called shadow puppetry as a form of entertainment. Cutout shapes were put in front of a light source, projecting images onto a screen. Musicians and singers used their talents to share the story the puppets were portraying. In the past you might have also participated in a similar form of shadow puppetry. Have you ever made a dog or rabbit shadow with your hands in front of a projected light? If so, you have created shadow puppetry. Using the keywords "hand shadow puppetry" many examples can be found on the internet on how to create different shadow creatures with your hands. Light and shadows have long been used to make art and tell stories. However, the contrast created between light, shadow and imagery can also be important in understanding concepts in science.

Stereology involves interpreting 2-D images from thin cross-sections of 3-D objects to determine its 3-D shape. Scientists use these methods to help piece together a 3-D object when only 2-D slices are available for viewing. Have you ever heard of a CT or CAT scan? They are two abbreviations for the same X-ray cross-sectional imaging process. In computer tomography $(\mathrm{CT})$ or computer axial tomography (CAT) cross-sectional x-ray images are taken of the body for diagnostic purposes. Tomo, the base of tomography, comes from the Greek word meaning slice or section. CT scans are x-ray images that depict thin, cross-sectional images of the human body. They are used, for example, for identifying of possible traumatic brain injury. Physicians study cross-sectional images from the CAT scan to measure for possible swelling or bleeding in the brain.

Real-life applications of stereology are diverse, from historical perspectives on how microscopic structures are determined to understanding functions of skeletal muscles. An example from research is using micrographs of the 2-D structure of the skeletal muscle to conceptualize the 3-D structure and propose the sliding filament hypothesis of how skeletal muscle contracts.

Dimensions of 3-D objects such as biological tumors or even small objects observed in electron photomicroscopic images can be calculated from measurements of the 2-D images. In medicine such data are used for assessing possible treatments for tumors or other experimental procedures. However, measurement errors must be accounted for in calculating the object's true size.

The reliability of reconstructed 3-D object dimensions from 2-D cross-sectional images is limited by the depth of the cross-sections. Two-dimensional images obtained with electron microscopy can only create slices of thin sections in the range of $75 \mathrm{~nm}$ in normal practice. So, reconstruction of objects thinner than $75 \mathrm{~nm}$ is challenging. Also, when fragments are presented in end sections of a series of cross-sectional images, the true sizes are not directly measured because the projected image does not provide the real dimensions, so estimates have to be used (Atwood and Cooper, 1996; Kim et al., 2000).

Accounting for measurement error is important when inferring sources of altered function. For example, when researchers are examining mutations in proteins of biochemical process, such as location of synaptic vesicles within nerve terminals, knowing the error in measurements is important to determine if structural differences can account for altered function (Johnstone et al., 2011; Uteshev and Pennefather, 1997).

\section{Procedures}

It is best to use a stepwise approach when assembling the models. Create Module 1 first. Then build Module 2 on the base of Module 1 . 


\section{Module 1}

For this exercise we suggest creating an example specimen with a triangular structure because the errors and the projected images illustrate the main concepts.

\section{Part 1: Model Construction and Calculating 3-D Area of Object}

To begin construction of the model, cut a triangle from a piece of Styrofoam ${ }^{\mathrm{TM}}$ or other easily cut material that can be glued to the plastic container. The triangle's length should span parts of three small sandwich-size food storage containers. The two ends should only span half of the end containers. Now cut this triangle into thirds so that a section can be glued into each container. The middle section will extend the full thickness of the container. The two ends will project only halfway through each of the end containers (Fig. 1). Using glue or strong double stick tape, secure a section into the bottom of each container, aligning them so that when the containers are arranged end to end one can see the triangle shape from above (Fig. 1). A schematic version is illustrated in Figure 2A.

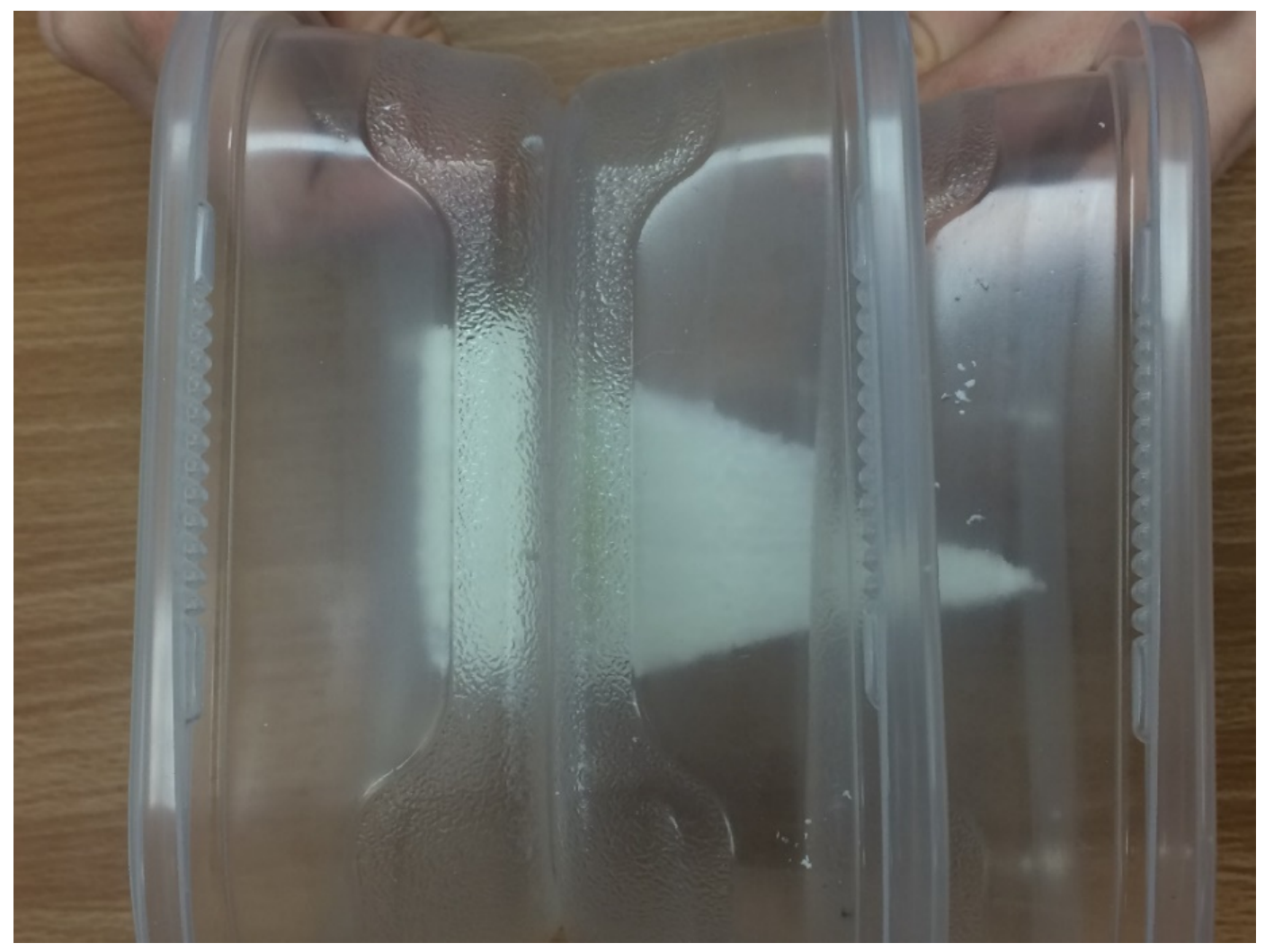

Figure 1. Top view of the sectioned triangular object placed into three containers. The two end sections only project halfway through the containers. 


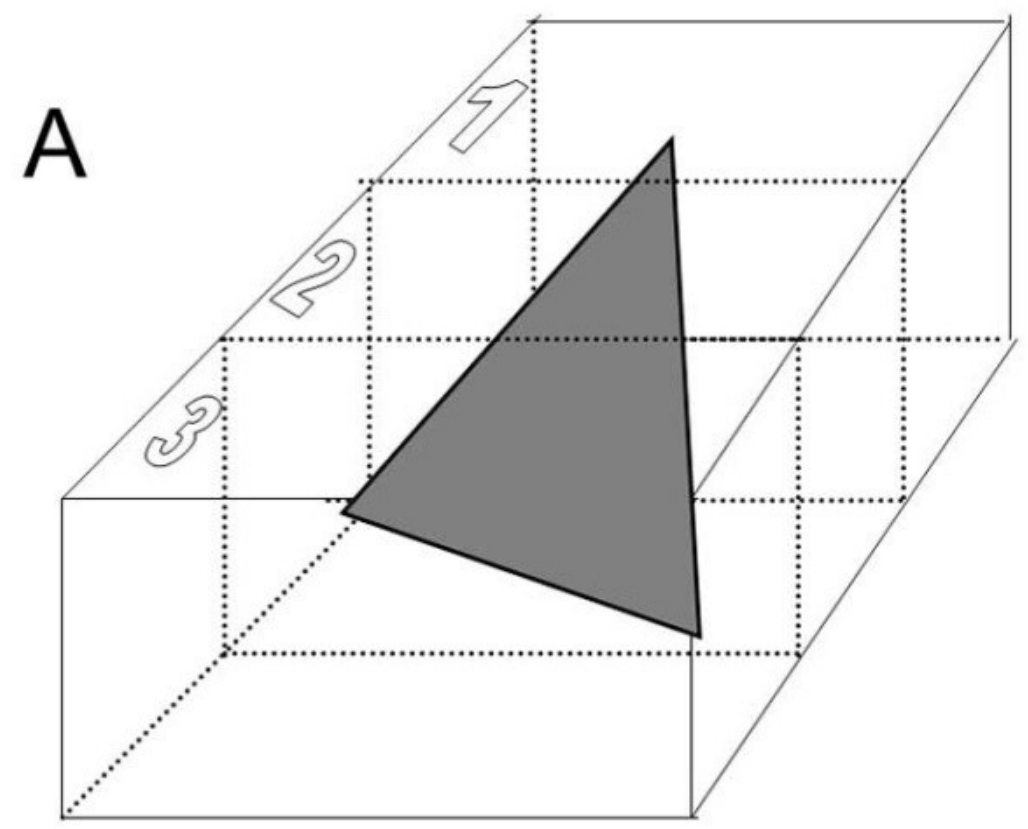

PROJECTED LINE

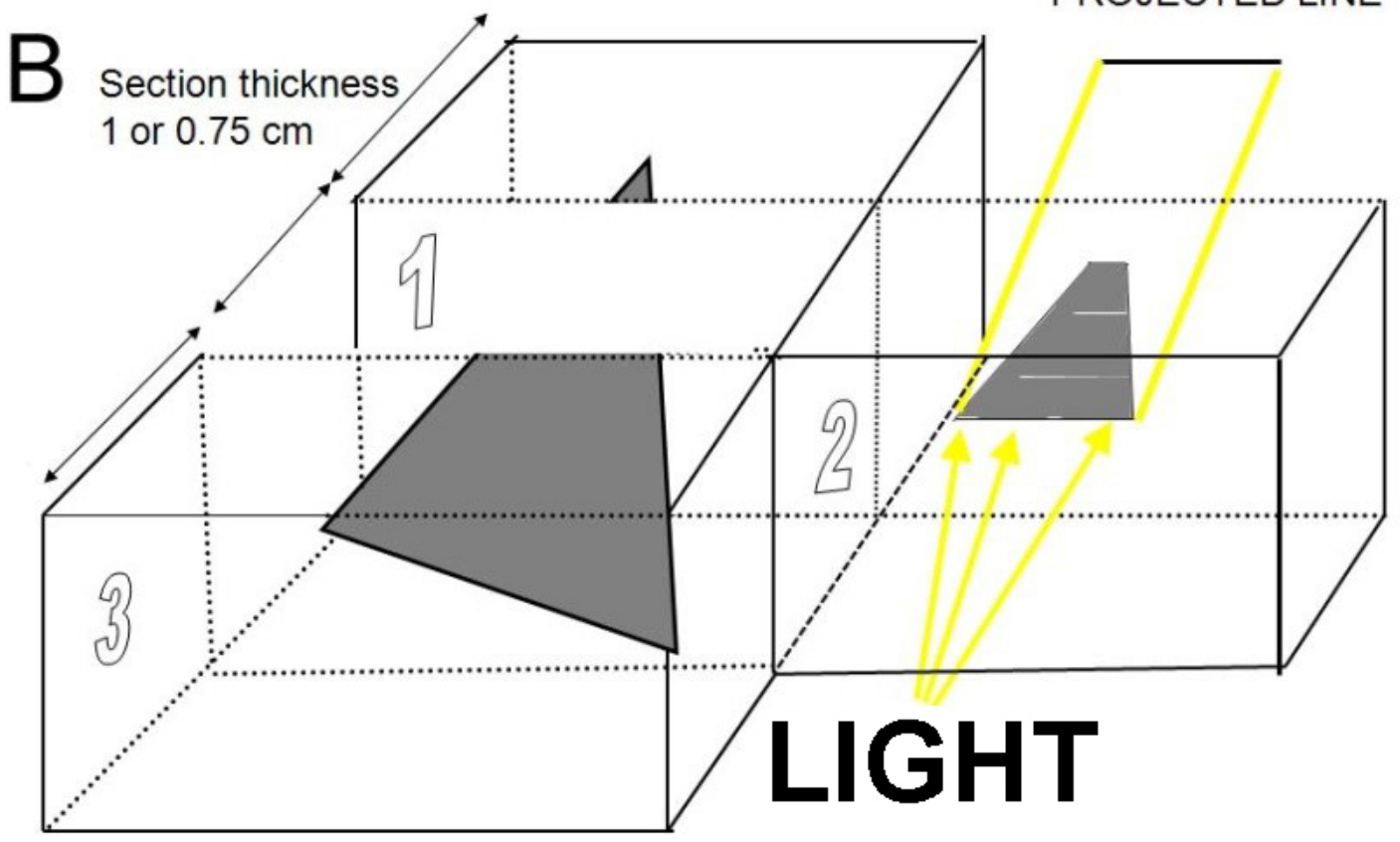

Figure 2. View of the sectioned triangular object placed into three containers. A) The three sections in series with the triangular object spanning halfway through the two end sections. B) The middle section is pulled out and a light is shined from the end of the section to show the projected line on the paper. The projected line is to be traced on graph paper. The same light projection is to be used for the two end sections for obtaining a projected line. As a team, one person should place a sheet of graph paper on the bottom of the food storage container. Now place the container on its side. Another student can shine a flashlight on the open end of the container so that a shadow 
appears on the graph paper (Fig. 2B). The student holding the graph paper should trace the outline of the shadow shape observed on the paper. Measure the length of the shadow shape and record it in a table (Table 1). Repeat this process for all three sections in the module, recording each measurement so it will be easy to compare results.

Next, calculate different versions of the estimated areas for the object observed in each section of the three containers (Table 1). You can combine the images on the graph paper from container sections 1, 2, and 3 to determine the surface area of the full structure.

Let's pause and think about what we might infer from the data we have collected and calculated. Our goal is to calculate a reliable estimate for the original 3-D figure's shape and volume from the 2-D images. We now have a 2-D image we constructed from the shadow created by shining the flashlight through the container. We also have calculated estimates of the surface area of the shadow shape. From these data, answer the following questions:

1. Using the shadow data, what is the shape of the original 3-D object? What evidence do you have to support your claim?

2. Do you believe there might be error in the estimated measures you have calculated? What evidence from the work you have done leads you to this conclusion?

3. If you believe there is error in the calculated measurements, what might be the sources of error? How might your team identify these sources of error?

The tabular worksheet will help you to recognize that even the best estimation of triangle's area from the 2D images will not create an accurate measurement of the original 3-D object's volume. Calculate the surface area of the image from the top or bottom view. You could assume the three projected lines are of rectangles in each section and that they project through the full section thickness (Fig. 3).

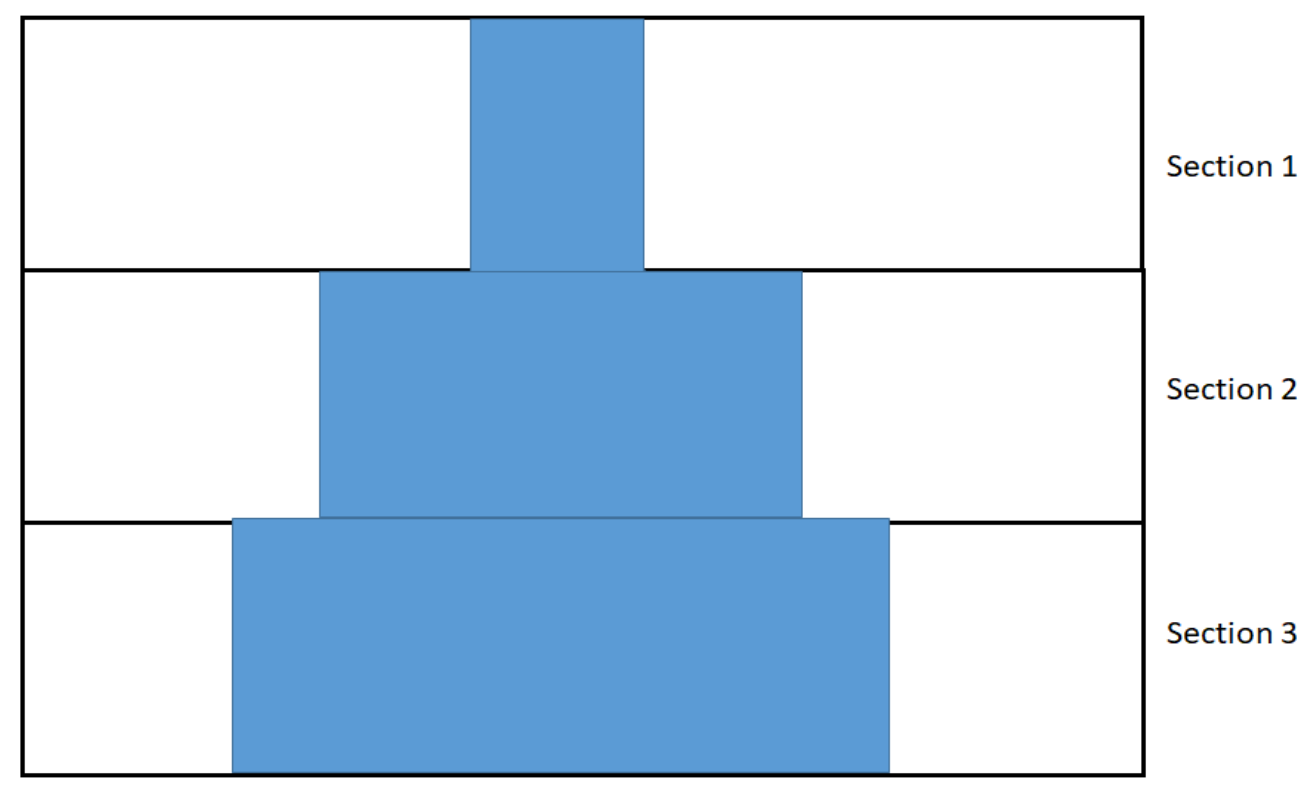

Figure 3. Top view of the sectioned object placed into three containers assuming the projected lines are from rectangles. The projected lines on the graph paper provide the length. The thickness of the containers provides the width of each section. Add the surface area for each section for a total surface area $\mathrm{cm}^{2}$. 
The information collected from the shadow figures drawn on graph paper shows that the two ends of the figure do no project all the way through the two end containers sections (sections 1 and 3). This information can be used to make a better estimate of the actual or true area of the 2-D shape.

In scientific practice, an average surface area is calculated for the two ends of the 2-D shape. This is done by conducting many trials using the same object and slicing it into three sections. There is expected error in measuring the area of the end sections, but by conducting many trials of finding the average area of these end sections, it is assumed that the average area calculated will be at an acceptable estimate to the actual area; one trial may not provide such a close estimate because of measurement errors. For the shape used in this exercise, an average area of the sections protruding into the end container sections would end up only projecting into half the width of each end section.

Figure 4 shows the estimated view of the triangular object if it protrudes only half the distance into each of the two end sections. Use this figure as a model for calculating the estimated area in $\mathrm{cm}^{2}$ of the two ends (in sections 1 and 3) drawn on your graph paper.

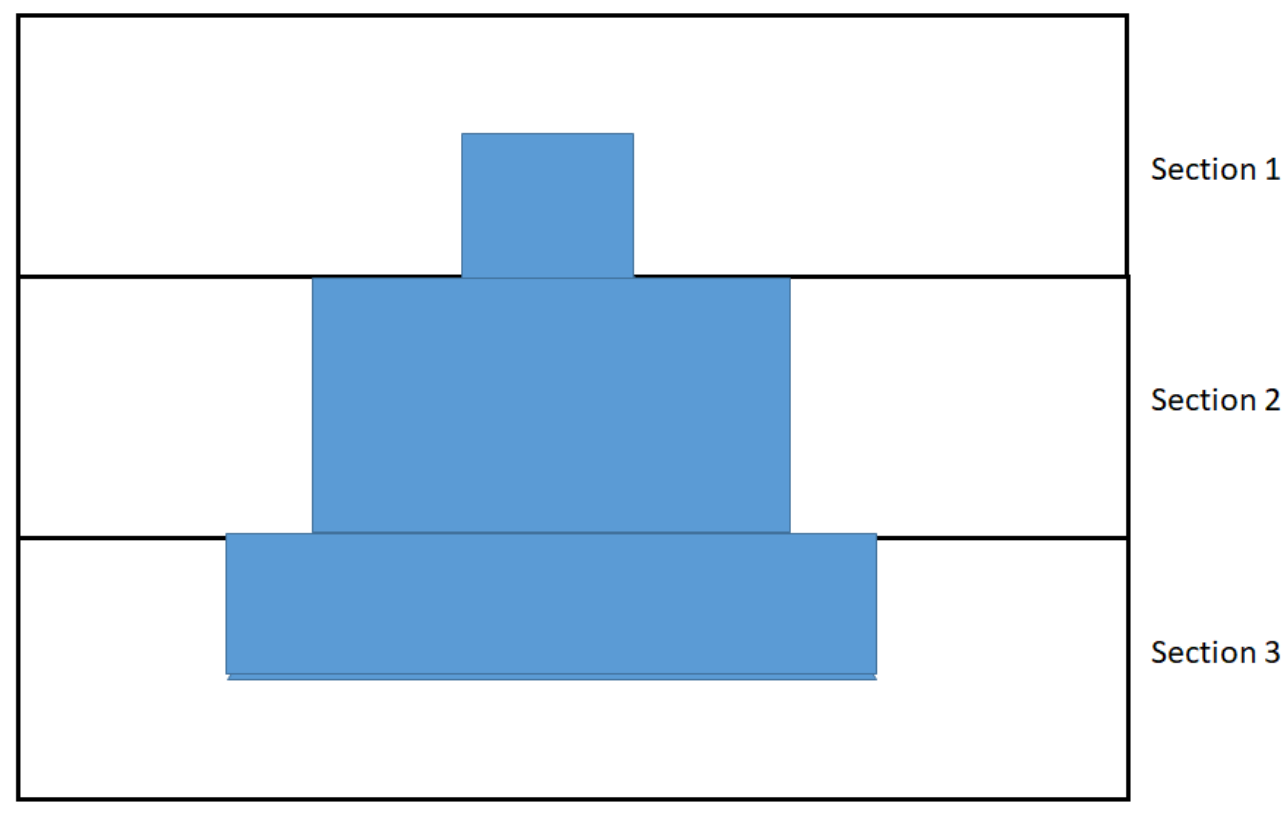

Figure 4. Top view of the sectioned object placed into three containers with only using half the width measurements for the two end sections. The projected lines on the graph paper provide the length. The thickness of the containers provides the width of each section. Add the surface area for each section for a total surface area $\mathrm{cm}^{2}$.

Now we can compare the calculated area of the rectangular structures projecting through the full thickness of all three containers to the calculated area of the two end sections where the rectangular structure projected only halfway through the container sections. And the true area of the triangle can be obtained by measures of a top view above all three sections (Fig. 5). 


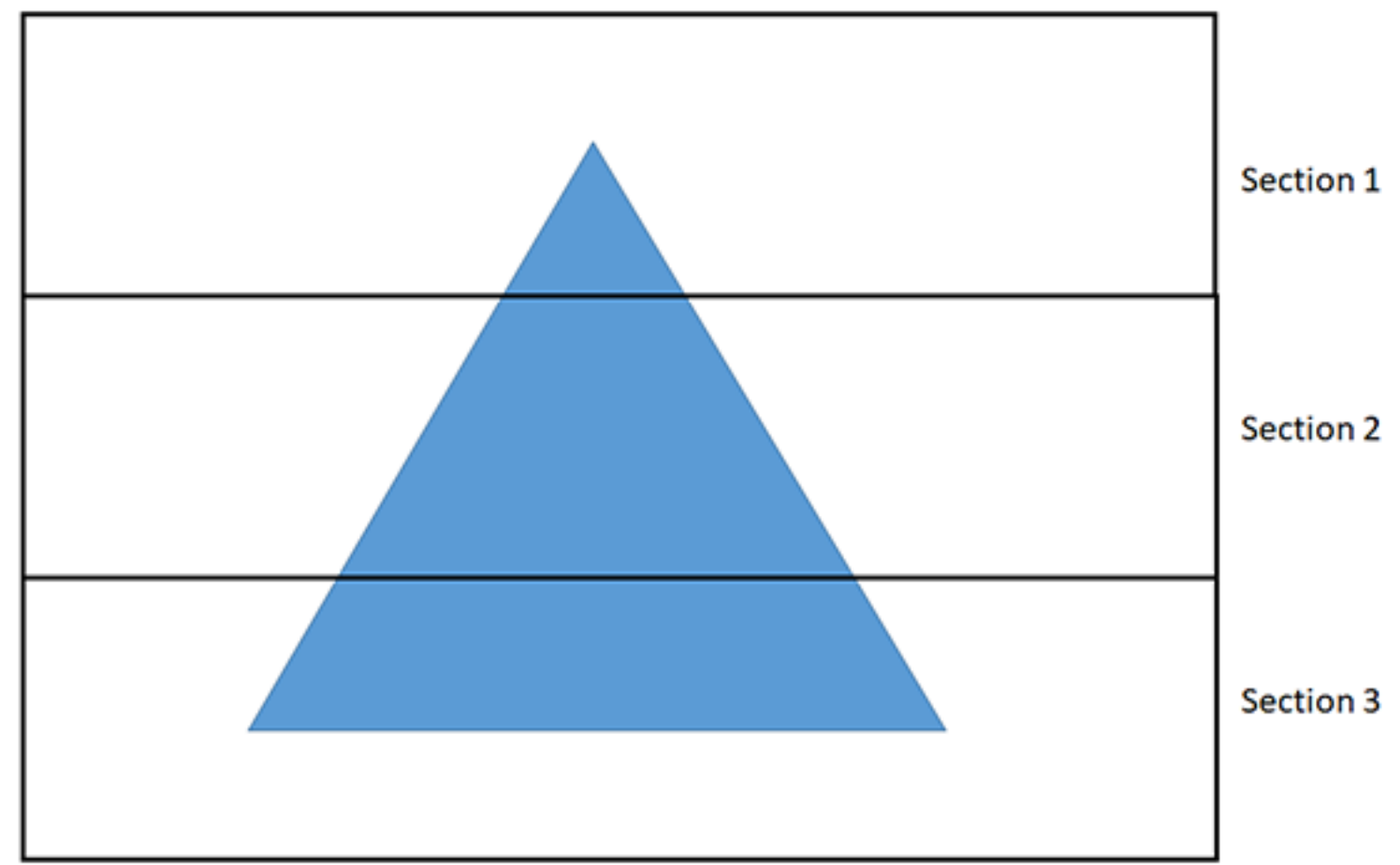

Figure 5. Top view of the sectioned triangular object placed into three containers. A sheet of graph paper can be placed underneath or above to trace this view of the triangular object. The surface area of this one side can be calculated in $\mathrm{cm}^{2}$.

The surface area measurements in the three approaches can now be compared in a table (Table 1).

\section{Discussion}

Questions:

1. Review your data. Which of the methods resulted in calculations that were closest to the surface area of the top view image? Which method resulted in estimated area farthest from surface area of the top view?

2. What sources of error do you observe in using each of the three methods for calculating the area of the 2-D object? 
Table 1. Estimated surface area measures using three different approaches.

\begin{tabular}{|c|c|}
\hline \multicolumn{2}{|c|}{ First measures of object projected through all three sections. } \\
\hline Section 1 Area & 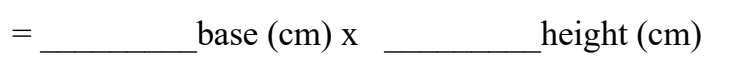 \\
\hline Section 2 Area $\quad \mathrm{cm}^{2}$ & 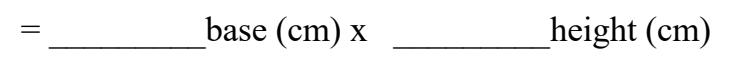 \\
\hline Section 3 Area $\quad \mathrm{cm}^{2}$ & $=$ \\
\hline Total Area: Sections $1+2+3$ & $=\mathrm{cm}^{2}$ \\
\hline \multicolumn{2}{|c|}{$\begin{array}{l}\text { Second measures of object projected through all three sections but only halfway for the two end } \\
\text { sections. }\end{array}$} \\
\hline Section 1 Area & 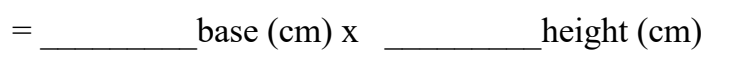 \\
\hline Section 2 Area $\quad \mathrm{cm}^{2}$ & $=\ldots$ base $(\mathrm{cm}) \times \quad$ height $(\mathrm{cm})$ \\
\hline Section 3 Area $\quad \mathrm{cm}^{2}$ & $=$ \\
\hline Total Area: Sections $1+2+3$ & $=\underline{\mathrm{cm}^{2}}$ \\
\hline \multicolumn{2}{|c|}{$\begin{array}{l}\text { Third measures of object projected through all three sections but measured from the top view of } \\
\text { the triangular structure (Area of triangle }=1 / 2 \text { base } x \text { height) }\end{array}$} \\
\hline \multicolumn{2}{|l|}{ Top view: area ___ $\mathrm{cm}^{2}$} \\
\hline \multicolumn{2}{|c|}{$\begin{array}{l}\text { Calculate the difference between the last two techniques (After removing } 50 \% \text { off the two end } \\
\text { sections to the top view approach). }\end{array}$} \\
\hline Difference: $\_\mathrm{cm}^{2}$ & \\
\hline
\end{tabular}

\section{Part 2. Identifying and Minimizing Measurement Error}

In reviewing the estimated area measures calculated in Part 1, there was one method that resulted in a closer estimate to the top view. That was the removal of half the distance projected into the two end sections.

Let us now think of a way to remove more of the error in the measures by looking at the projected slices on end. Notice the lines seem to jump in length between each section making it appear that the image is not a rectangle in each section, but a shape that gradually projects into the next section. An estimate of the original shape can be created form these lines by drawing incrementally wider or narrower rectangles stacked (Fig. 6), one on top of the other. To do this, assume each rectangle will project through half the thickness of each section, and one quarter (1/4) of the thickness of the end sections (that $1 / 2$ of the $1 / 2$ end section through which the object projects). 


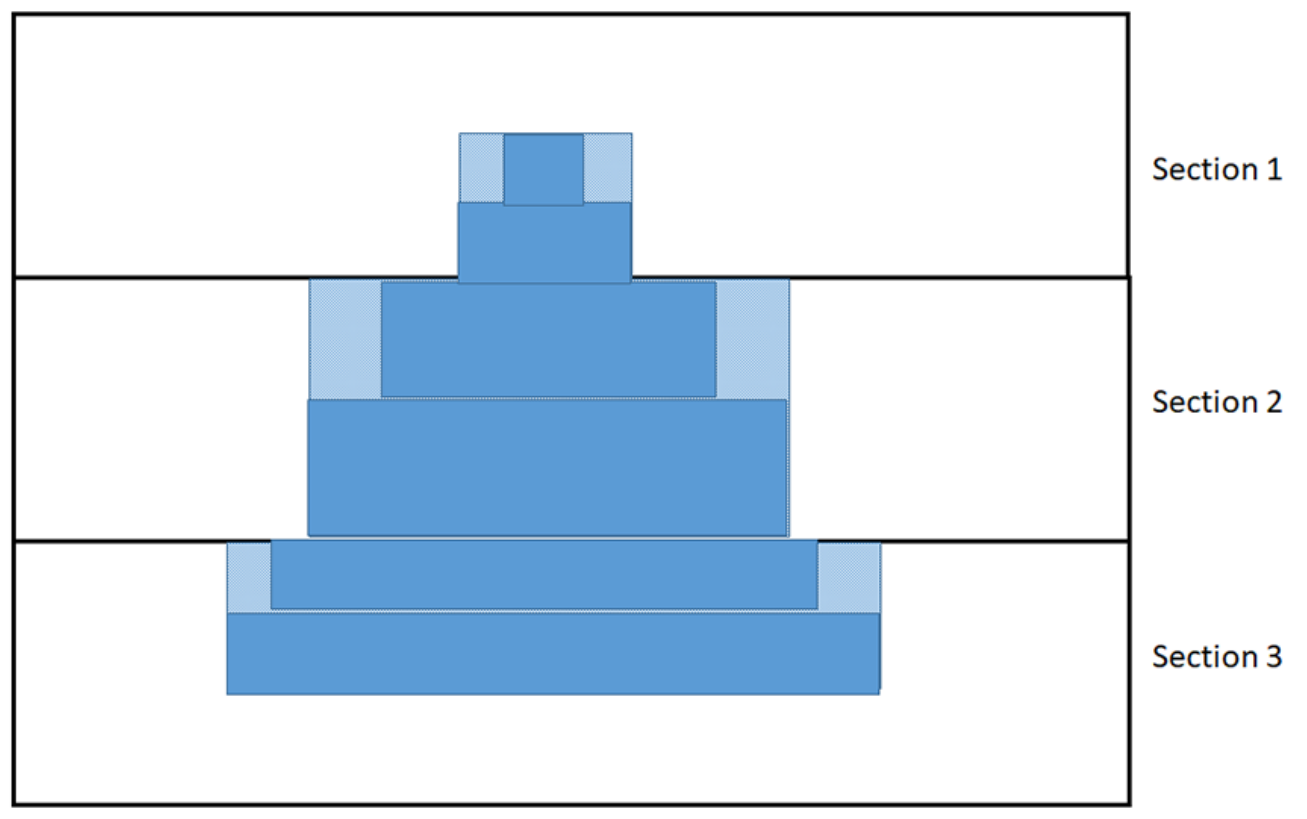

Figure 6. When looking down on the projected image from the top view, the observer can only see the edge of the object, which appears as a line. From this view, it may not be clear that the object does not project completely through all three sections. Following the edge of the form through each section, the projected lines gradually vary in length from one section to the next, indicating the object tapers in length within a section. Thus, the projected line in one section compared to the projected line in the next section in sequence indicates how much the object tapers within a section. Assuming halfway within the section the object tapers, then the half of the length that is reduced can be removed from each side of the rectangle (the light shaded parts). By looking at the sections from a top view, an estimation of the objects shape can be created by drawing rectangles staked one on top of the other, with the height of each rectangle being $1 / 2$ of the container section where the object projects through the whole section, and $1 / 4$ of the end sections where the object projects through only $1 / 2$ of the section. Then stair-step the thickness of the lines to the next projected line. Doing so will begin to reveal a similar shape as the original triangle shown in Figure 5. The projected lines on the graph paper provide the length. The thickness of the containers provides the width of each section. The measures of each rectangular object need to be recalculated for removing half of the distances on each end to the next section. Six rectangular objects now are measured for the total surface area. The shaded areas are what is removed from Fig. 4 above. Add the surface area for the six darkly filled objects for a total surface area $\mathrm{cm}^{2}$.

Calculate the difference between this last techniques of six rectangles (After removing $50 \%$ off the two end sections to the top view approach and stair stepping the ends).

Section 1:

$$
\begin{aligned}
& \text { Part } 1 \text { area } \_\mathrm{cm}^{2}(\text { base } \mathrm{x} \text { height }=\text { area }) \\
& \text { Part } 2 \text { area } \quad \mathrm{cm}^{2}(\text { base } \mathrm{x} \text { height }=\text { area })
\end{aligned}
$$

Section 2:

$$
\begin{aligned}
& \text { Part } 3 \text { area } \_\mathrm{cm}^{2}(\text { base } \mathrm{x} \text { height }=\text { area }) \\
& \text { Part } 4 \text { area } \_\_\mathrm{cm}^{2}(\text { base } \mathrm{x} \text { height }=\text { area })
\end{aligned}
$$

Section 3:

Part 5 area ___ $\mathrm{cm}^{2}$ (base $\mathrm{x}$ height $=$ area $)$ 
Part 6 area $\mathrm{cm}^{2}($ base $\mathrm{x}$ height $=$ area $)$

Total area of six parts: area $\mathrm{cm}^{2}$

The difference in top view of triangle (part 1) and this latest approach.

Difference:

$\mathrm{cm}^{2}$

Note the difference in measures between those in Part 1 and the most recent measures calculated in Part 2. The measure difference is becoming smaller in comparison to the earlier measures in Part 1. In fact, there is nearly $50 \%$ error in the true area calculated for the 3-D object in Part 1 when using a top view in comparison to the end section calculations used in Part 2. Share with other groups in the class the various means calculated when estimating the errors.

An alternative method for calculating the volume of a 3-D object from 2-D surface area can be done using drawings on graph paper. First construct drawings similar to those constructed in Part 2 above using the stairstepping method to construct the rectangular pyramid shape. Then draw horizontal lines to identify the top and bottom of each section of the rectangular. Figure 7 illustrates using this method to compare the area of two shapes, one with three sections (A) and a second with four sections (B). One can use the full rectangle in each section for this exercise. The section thickness is $1 \mathrm{~cm}$ each for the three sections and $0.75 \mathrm{~cm}$ each for the four sections.

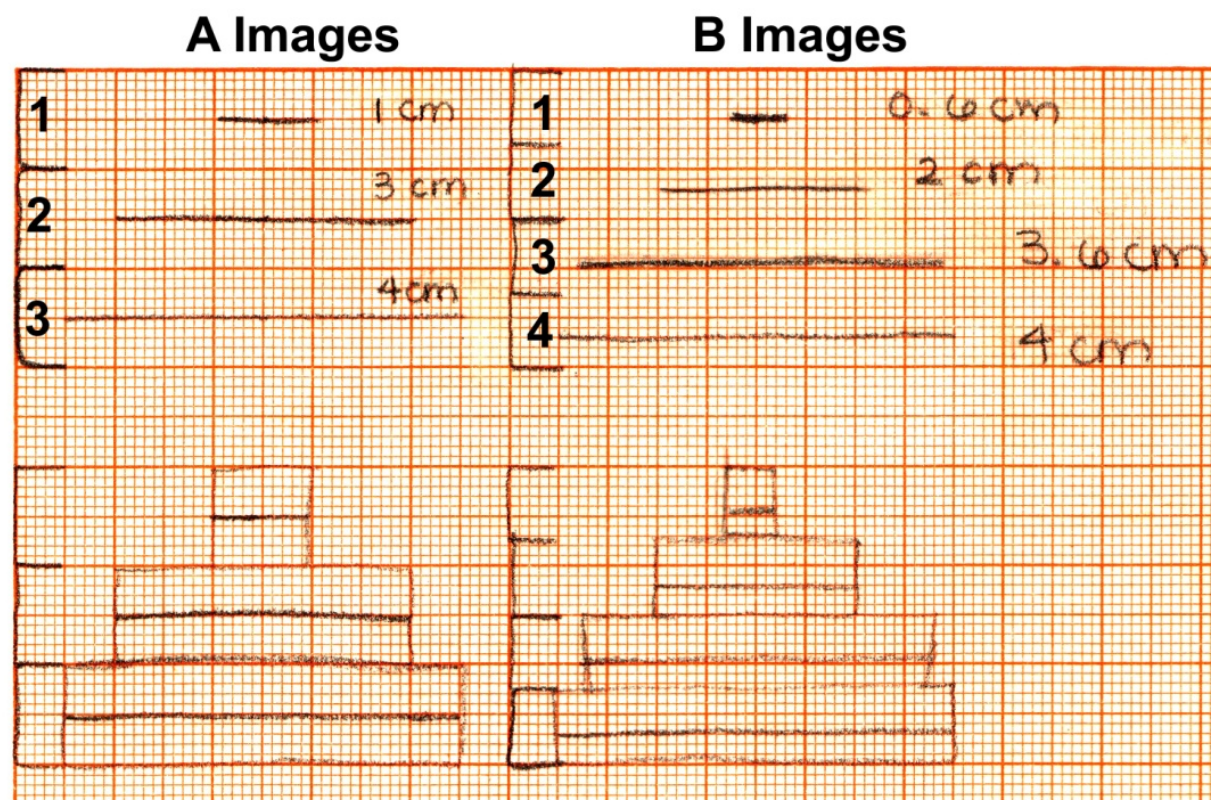

Figure 7. The view as shown looking down from the top as in the bottom half of this figure. The lines in the top are the projected lines as would be seen with a light projecting through each section. The series of $\mathrm{A}$ images are for three sections and the series for the B images are for four sections of the same object.

The true structures of the objects used for this problem are shown in Fig. 8. Calculate the true area and determine how much their estimates are off compared to the top view looking down. 

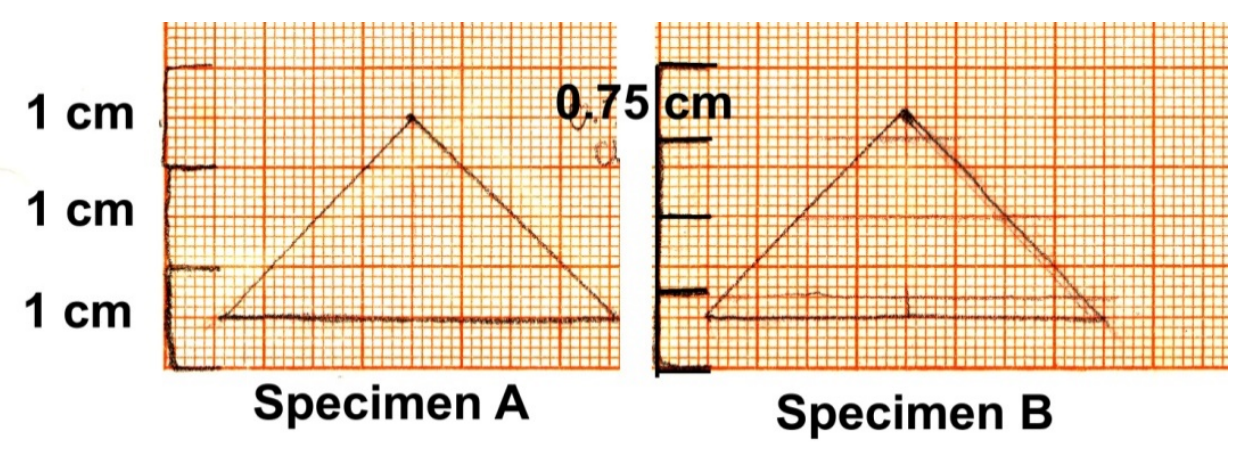

Specimen B

Figure 8. The true structures of the objects shown in Fig 6.

\section{Computational Imaging of 3-D Structures and Rotational Views}

Open Source modeling software can be used to easily manipulate 3-D objects to see how they might appear from a 2-D view. Download the freeware version of SketchUp (see https://www.sketchup.com/plans-andpricing/sketchup-free ). One can draw most any object within the software and rotate it in 3-D as well as to view the objects in their 2-D form.

\section{Module 2}

The second half of this module is more advanced and might be best suited for students who have finished geometry and are beginning pre-calculus. Module 2 is presented in Appendix A of this activity.

\section{Discussion}

As you have learned, there are a variety of strategies to determine surface area (2-D) or volume (3-D) of known geometric structures using graphing techniques. You had to use basic equations to determine area, and if you conducted Module 2, you might have used calculus-based approaches. The series in the approaches presented in these exercises illustrates how you might systematically go about resolving questions to obtain better measurements of the true structure of an object.

Consider the real-life connections in this module. How much error is acceptable for the measurements made? If a drug has the potential to reduce the volume a tumor by $5 \%$, is it worthwhile based on the calculated measurements of the tumor? Is a 5\% measurement error of a tumorous mass acceptable in determining whether a cancer drug is working? Is the $5 \%$ measurement error an issue when considering whether to offer the cancer drug or opt for an alternative approach?

In another example, consider how the distance between synapses - structures between a neuron and a target tissue - might affect physiological processes. In measuring the distance between synapse and target tissue, what is the acceptable percentage of error? How will error in measurements affect communication for physiological processes? How might measurement error affect conclusions that have been drawn about the communication between neurons and nearby tissues?

\section{Cited References}

Atwood HL, Cooper RL. 1996. Assessing ultrastructure of crustacean and insect neuromuscular junctions. Journal of Neuroscience Methods 69:51-58.

Coll RK, France B, Taylor I. 2005. The role of models/and analogies in science education: Implications from the research. International Journal of Science Education 27(2):183-198.

Gilbert JK, Boulter CJ, Elmer R. 2000. Positioning models in science education and in design and technology education. In JK Gilbert and CJ Boulter (Eds.), Developing modesl in science education. Dordrecht, The Netherlands: Kluwer.

Johnstone AFM, Viele K, Cooper RL. 2011. Structure/Function assessment of crayfish neuromuscular junctions. SYNAPSE 65(4):287-299. 
Kim S, Atwood HL, Cooper RL. 2000. What are the real sizes of synaptic vesicles in nerve terminals? Brain Research 877:209-217.

NGSS Lead States. 2013. Next Generation Science Standards: For States, By States. Washington, DC: The National Academies Press.

Lane SM, Mathews RC, Sallas B, Prattini R, Sun R. 2008. Facilitative interactions of model- and experience-based processes: Implications for type and flexibility of representation. Memory \& Cognition 36(1):157-116.

Mayer RE. 1989. Models for understanding. Review of Educational Research 59(1):43-64.

McNeill KL, Krajcik J. 2008. Scientific explanations: Characterizing and evaluating the effects of teachers' instructional practices on student learning. Journal of Research in Science Teaching 45(1):53-78.

Seel NM. 1991. Weltwissen und mental Modelle. Göttingen: Hogrefe [World knowledge and mental models]

Seel NM. 2017. Model-based learning: A synthesis of theory and research. Educational Technology Research and Development. 65(4):931-966.

Schwarz CV, Reiser BJ, Davis EA, Kenyon L, Achér A, Fortus D, Shwartz Y, Hug B, Krajcik J. 2009. Developing a learning progression for scientific modeling: Making scientific modeling accessible and meaningful for learners. Journal of Research in Science Teaching. 46:632-654.

Ucar S, Trundle KC. 2011. Conducting guided inquiry in science classes using authentic, archived, web-based data. Computers and Education. 57(2):1571-1582

Uteshev VV, Pennefather PS. 1997. Analytical description of the activation of multi-state receptors by continuous neurotransmitter signals at brain synapses. Biophysics Journal 72:1127-1134. 


\section{Materials}

The following materials are needed to perform these activities and they are all obtained at a local craft store or retail outlet (i.e. Wal-Mart):

- Clear, sandwich-size food storage containers. They should be thin and easily allow light to shine through the bottom

- $\quad$ Styrofoam ${ }^{\mathrm{TM}}$

- Exacto $^{\mathrm{TM}} \mathrm{knife}$

- $\quad$ Super glue TM

- Graph paper

- Flashlight

- Pens or markers

- Module Worksheet

- Computer for the program SKETCH UP to be used.

\section{Notes for the Instructor}

These modules are designed for students with various levels of background in math and life sciences. They can be conducted with more advanced students following the module instructions presented in the student section or modified for less advanced students to illustrate challenges of inferring 3-D objects from 2$\mathrm{D}$ images. Another topic related to stereology is the workings of a stereoscope. These devices, made popular in the $1800 \mathrm{~s}$, placed images in front of each eye so that the same image could be seen in only one eye. When both eyes observed the two images through a set of lenses, they create a 3-D effect.

This module is narrated online via YOUTUBE by Ms. Maddie Sanden as an overview (https://www.youtube.com/watch? $\mathrm{v}=\mathrm{cRkZMDCGRB}$ $0 \&$ feature $=$ youtu.be) and for visualization of the steps for Module1

(https://www.youtube.com/watch?v=aP1SmSAw5OU $\underline{\& x-y t-c l=85114404 \& x-y t-t s=1422579428)}$.

Additional material is also presented

online. Please see:

http://web.as.uky.edu/Biology/faculty/coope r/ABLE-2019/Imaging\%20science-Stereology/ Home-stereology.htm

These modules allow a wide variety of approaches to be implemented depending on the classroom as well as ease in modifications from year to year. This provides an opportunity for the instructor to obtain a mix of the data to be collected for novel reports and varied discussions among classes. We have discovered the outcome of students taking the measures and comparing their data is eye opening. Students realize there is a multitude of ways to address a problem and obtain similar answers.
Instructors will need to be prepared to scaffold students in constructing the models and calculating error. After assembling the models, students will need some guidance on how to calculate error. Prepare questions that can be used to guide students through the work rather than simply giving them the answer. Supporting students in reasoning through problem-solving supports the development of critical thinking, perseverance, and is one of the goals of the modules. Periodically interrupting student work to ask for examples of problem-solving strategies students have employed will help other students that are struggling with model construction and calculating the 3-D objects' area and accompanying error. Supporting multiple approaching to solving problems effectively promotes reasoning and critical thinking skills. Instructor questions and student-provided examples for problem solving scaffold students' learning. Also consider having multiple worked examples available in the case some students need further support. In addition, holding the objects in different orientations from the light also can help students visualize slices of images they are constructing in the models in comparison to 3-D objects. Tilting the object when shinning the light at different angles can demonstrate the shape in very thin cross-sections that are often used in research.

A pre- and post-test sample is also provided in Appendix B. The same test is used for both pre and post tests

We implemented this exercise for nonscience majors by providing a generalized PowerPoint presentation to introduce and explain the activity. Then students were divided into groups to work on activities associated with different objects made out of Styrofoam $^{\mathrm{TM}}$ cut into 3 sections and mounted into sandwich-size food storage containers as shown in Figure 1 (a sphere, a triangle, a rectangle). In the follow-up class discussion, the middle school students were able to describe differences they observed in the appearance of the 2-D images observed in the models in comparison to the actual 3-D objects. From these observations they were able to recognize errors in their inferences of the original 3-D objects based on the projected series of 2-D images. The graph paper activities described in Part I of the first module well require extra time beyond a 50 minute class period. Time constraints also limited our ability to post-test students who tested this module for us. Pre-test results collected before instruction are provided in Appendix B. Pre-test results and discussion responses following instruction suggested that the topic was likely too advanced for the non-science based students sampled. While class discussion responses illustrated students' conceptual understanding of misconceptions that can arise when inferring a 3-D object's shape from 2-D 
images, identifying error in calculating the original object's volume from the surface area of 2D images, and minimizing measurement error are appropriate for students with more advanced mathematical and abstract reasoning skills. If students appear to be struggling with Module 1 in conceptulaizing what the projected lines might represent as retangles then maybe the figures of what a top view would look like in Module 2 could support the students struggling to make sense of the line drawings.

\section{Assessment}

There are several nuances to this activity and the calculated data sets to allow groups. of students within a classroom to give oral presentation, a written report and/or demonstration of physical or computational models on different aspects they covered. Numerical values can also be obtained and compared across groups to initiate a discussion to account for differences in measurements, acceptable percentages of error, and reasons to support error allowances.

\section{Acknowledgments}

Funded by personal funds (RLC). We thank Dr. Christine Schnittka for the suggestion to make the modules small enough and easy to assemble and store in classrooms.

Ann O'Neil is a physical therapist at Cincinnati Children's Hospital. She received a B.S. in Topical Studies Neuroscience and a DPT degree from the University of Kentucky. She is a certified clinical instructor and interested in becoming a Neurologic Clinical Specialist.

Rebecca Krall is an associate professor in science education in the STEM Education Department at the University of Kentucky. She teaches science methods and technology integration in STEM education. She earned a BA in elementary education with certification in K-8 science and literacy from Virginia Tech in 1988, and a Master of Arts and Doctor of Philosophy in science education from the University of Virginia in 2000 and 2004, respectively. She has been at the University of Kentucky since 2003 and focuses her research on developing science teachers' knowledge and pedagogy to support authentic learning experiences in science.

Maddie Sanden graduated from the University of Kentucky with a BS in Mathematics and a minor in Neuroscience in 2017.

Robin Cooper is an instructor of animal physiology and neurophysiology at the University of Kentucky. He received a double major with a B.S. from Texas Tech in 1983 and a PhD in Physiology from Texas Tech Medical School in 1989. He has been at the University of Kentucky since 1996. 


\section{Appendix A: Module 2}

The second half of this module is more advanced and would be best suited for students who have finished geometry and are starting pre-calculus.

Part 1 should be completed before starting Part 2. In regard to the shadow box approach as mentioned in Part 1, instead of drawing a line on the graph paper, a height of the object (not the section width) now becomes important in estimating volume of the object.

For a more advanced aspect to determining area for a pre-calculus class, the surface area of the potential objects could be estimated by using fine-grid graph paper and using Simpson's Rule. Also, the object could be sliced into three pieces as in Part 1 and Simpsons rule to calculating area could be applied.

Instead of slicing the object into 3 slices, the given object could be sliced into 4 sections and volume estimated with including the error for the end sections can be used as a comparison for only using 3 slices.

For more of a challenge, the volume of the triangular object can be tackled and the error in volume. This can be related to 3-D imaging in MRI machines and the level of section thickness used for the size of the object with an acceptable error in estimating volume. However, the various sections in a triangular volume is challenging. The volume can be approached by using geometry $\left(1 / 2 b^{*} \mathrm{H} * \mathrm{~W}\right)$ for a true measure and compared to the estimated measures obtained by the projected images and taking the various errors in measurement for the end sections as well as the between sections.

For calculus-based students, a triple integral can be used to determine volume and compared to the geometric approach as well as to the estimates from the projected lines with thickness. There are various movies posted on YouTube to help explain the steps of how to set up the triple integral to calculate volume of a triangular prism.

http://www.mathopenref.com/prismtrivolume.html

\section{https://www.youtube.com/watch?v=E9itLQAoPdE}

When analyzing obtained data for Part 2, it is best to have worksheets with the paradigm used ( 3 or 6 slices, with or without error for ends and edges). Separate worksheets for area and volume would scaffold student work and aid them in completing the task.

The steps in Module 2 are as follows:

Imagine you are a scientist that is sent two specimens that have a 3-D configuration. The two specimens have the same size, volume, shape, and are $1 \mathrm{~cm}$ in height. The only difference between the two specimens is that one has 3 sections that are $1 \mathrm{~cm}$ in width and the other has 4 sections that are $0.75 \mathrm{~cm}\left(\mathrm{or}^{3} / 4 \mathrm{~cm}\right)$ in width. The specimens were sent to you already sectioned. You are to determine which technique is best for approximating the real volume of the specimen.

To view the sections, you shine a light from the side of the sections to view a shadow on a 2-D plane (Fig. 9). 


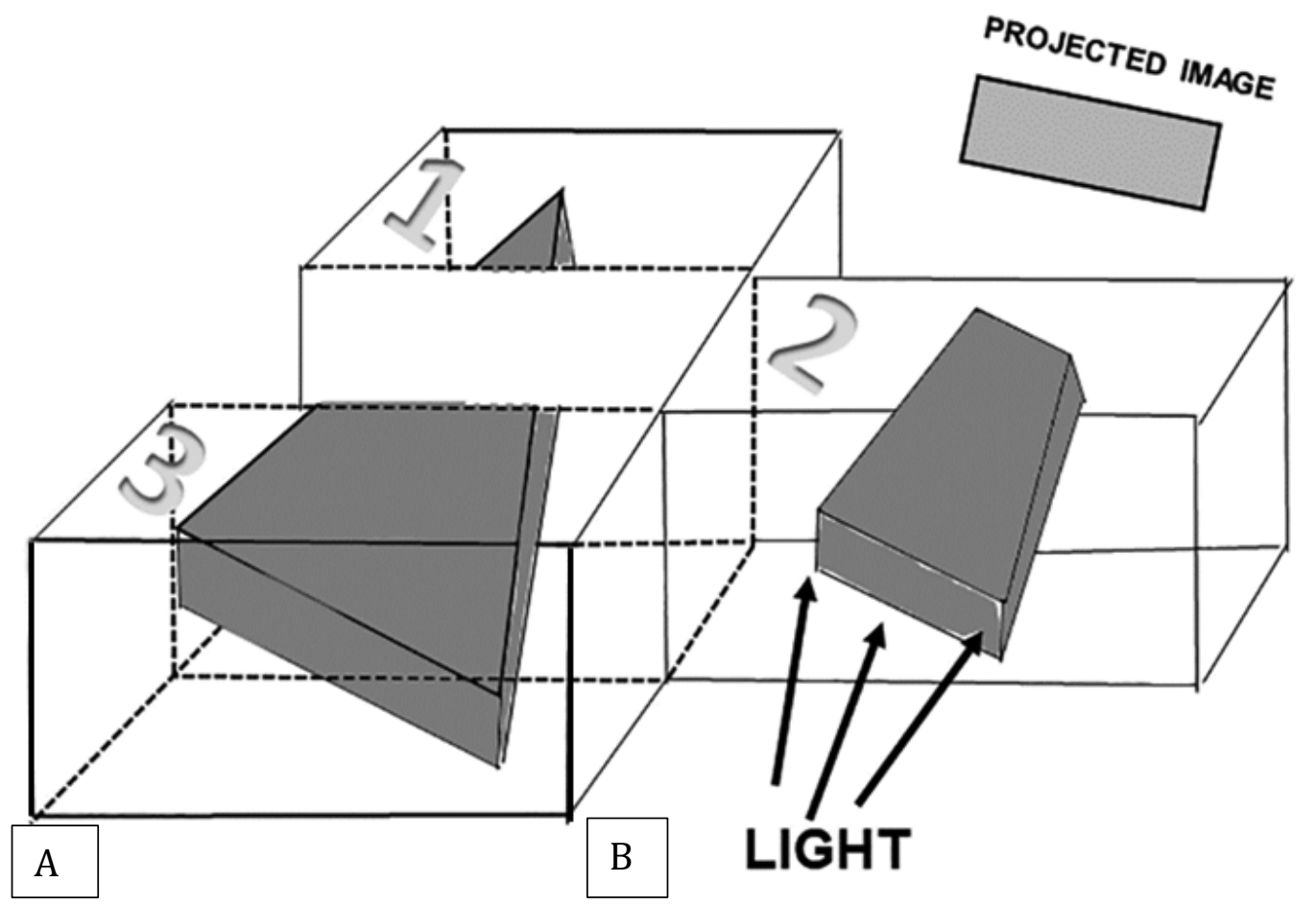

Figure 9. View of the sectioned triangular object placed into three containers. A) The three sections in series with the triangular object spanning halfway through the two end sections. B) The middle section is pulled out and a light is shined from the end of the section to show the projected rectangular 2D image on the paper. The projected triangle is to be traced on graph paper. The same light projection is to be used for the two end sections for obtaining a rectangle. 
The sections you see below (Fig.10) are the projected images of both specimen A and B. Remember, Specimen A is sectioned into 3 slices and specimen B is sectioned into 4 slices. The only difference between the two specimens is that one has 3 sections that are $1 \mathrm{~cm}$ in width and the other has 4 sections that are $0.75 \mathrm{~cm}(\mathrm{or} 3 / 4 \mathrm{~cm})$ in width.

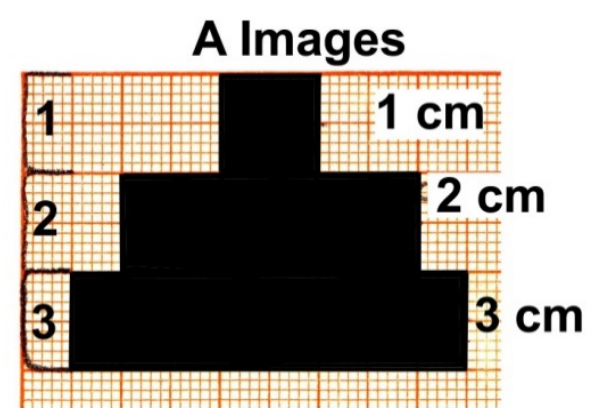

\section{B Images}

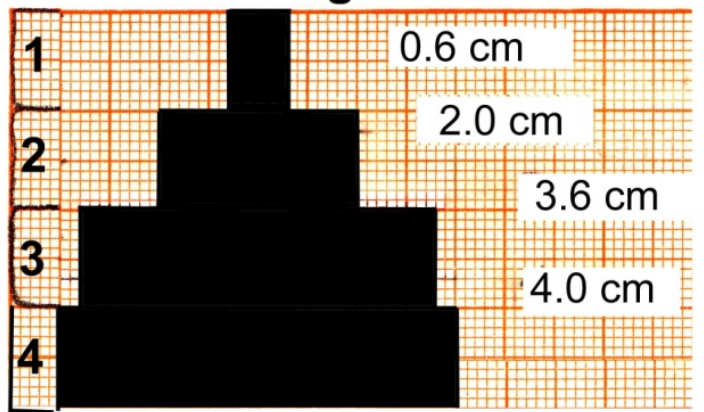

Figure 10. The view as shown looking down from the top of the stacked rectangular projected images. The rectangles in the top are the projected rectangles as would be seen with a light projecting through each section. The series of A images are for three sections and the series for the B images are for four sections of the same object.

\section{Part 1.0: Determining the Volume from the Sections}

Draw the estimated shape of the specimens determined from the rectangular sections shown above. The section that is projected is the length of a section. For example, if there were 2 sections that were projected (Fig. 11), you would draw the specimen as shown.

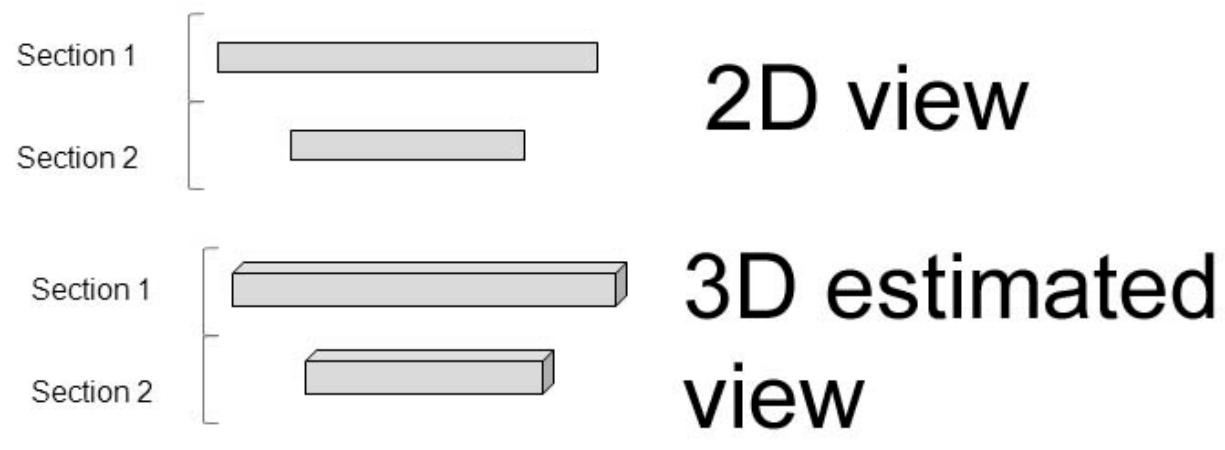

Figure 11. The volume of the estimated objects need to be calculated with thickness of the section and multiplying it by the height of the object and horizontal length. (Figure made by authors). 
After you have drawn specimens A and B, calculate the volume of the specimens (Note: $V=$ length $\times$ width $\times$ height; height $=1 \mathrm{~cm}$ ).

Specimen A:

Specimen B:

Section 1:

Section 1:

Section 2:

Section 2:

Section 3:

Section 3:

Total Volume:

Section 4:

Total Volume:

\section{Part 1.1: Difference between the Two Techniques}

Difference:

Calculate the difference between the two volumes from the two techniques.

\section{Part 2.0: Determining the Area with an Edited Version of the Sections}

In part 1.0, you drew the specimens as sort of a stair-step view. Usually for a cell specimen the projected sections would not cover the whole section. To fix this problem, draw a new picture for specimens A and B where the projected image does not cover the whole section width but $1 / 2$ its width to correct for the large stair step between sections. On average with random sections this would occur as $1 / 4$ the width between sections. For example:

If you were given the same slices as in part 1.0, the edited version would be drawn as shown (Fig. 12). To draw the edited version, draw lines (A) on the halfway point on surface A and C. Then draw a line to match the same length of the next smaller section. The smallest section is left alone because if any changes were made, the projected image would have been altered.
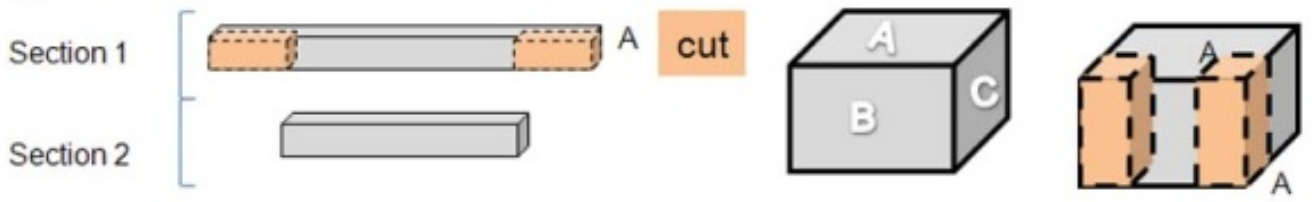

Figure 12. Removing estimates of the steps from one section to the next. Half of a section thickness and half the horizontal length from each end (left and right) which would be length of the step wise increment. The volume in orange is removed.

After drawing an edited version for both specimens A and B, calculate the volume. Specimen A:

Section 1:

Section 2:

Section 3:

Total Volume:

\section{Part 2.1: Difference between the Two Edited Techniques}

Calculate the difference between the two edited techniques.
Specimen B:

Section 1:

Section 2

Section 3

Section 4:

Total Volume:

Difference: 


\section{Part 2.2: Comparing the Difference between the Edited Techniques to the First Technique}

Calculate the difference in volume for specimen A and B from part 1.0 to part 2.0.

Difference for Specimen A:

Difference for Specimen B:

\section{Part 3.0: Determining the Volume with a More Realistic Edited Version of the End Sections}

In part 2.0, you determined the volume when the projected sections went to the edge of the section. In reality not all specimens go to the edge of the sections. Redraw specimens A and B with another technique. For example:

Take the same drawing done in part 2.0 and take off half of the width in the end sections. To do this draw line (B) down a fourth (1/4) of the way from surface A and C (step 1). Then on the smallest section draw a line a fourth (1/4) at the end of that section (step 2). The highlighted parts of the sections are the parts that will be removed. This method corrects for end sections as well as the large stair step effect on average.
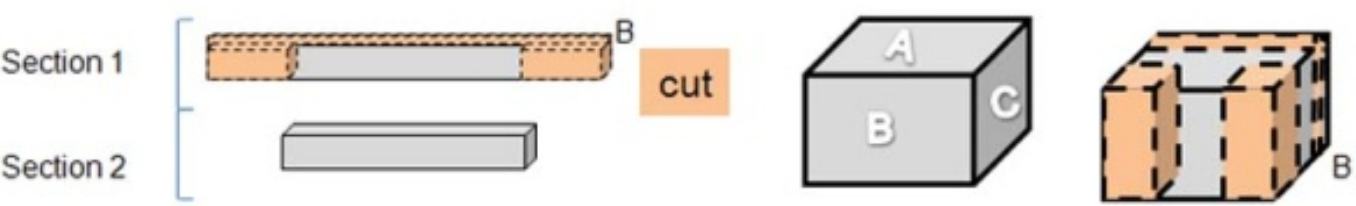

Step 2
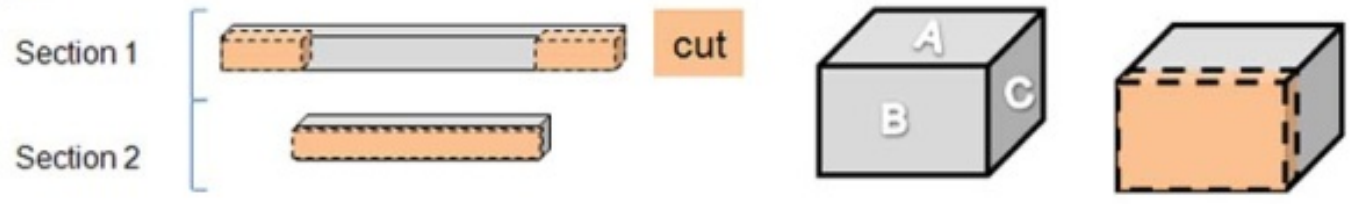

Figure 13. Removing the estimated volume from the two end section assuming the objects only projected half way through the two end sections. The volume in orange is removed.

After drawing the new edited version for both specimens A and B, calculate the volume.

Specimen A:

Section 1:

Section 2:

Section 3:

Total Volume:
Specimen B:

Section 1:

Section 2:

Section 3:

Section 4:

Total Volume:

Part 3.1: Difference between the Two New Edited Techniques

Calculate the difference in volume between specimen A and B.

Difference:

Part 3.2: Compare the Difference Between the New Edited Techniques to the First Edited Techniques.

Calculate the difference in volume between specimens A and B from Part 3.0 to 2.0.

Difference for Specimen A: 
Difference for Specimen B:

Part 3.3: Compare the Difference Between the New Edited Techniques to the First Techniques.

Calculate the difference in volume for specimen A and B from part 3.0 to Part 1.0.

Difference for Specimen A:

Difference for Specimen B:

\section{Part 4.0: Calculating the Real Volume of the Two Specimen}

The specimens were actually shaped as triangles. Calculate the two volumes for both specimens A and B from the figures given of the true structure. (Note: Volume of a Triangular Prism=1/2 $\times$ length $\times$ height $\times$ width)

Specimen A Area:

Specimen B Area:

Part 4.1: Comparing the Three Techniques to Find Volume in Relation to the True Volume

\begin{tabular}{|l|l|l|}
\hline & Specimen A & Specimen B \\
\hline Volume from Part 1.0 & & \\
\hline Volume from Part 2.0 & & \\
\hline Volume from Part 3.0 & & \\
\hline Volume Area & & \\
\hline
\end{tabular}

Place a checkmark next to the technique that is most similar to the real volume.

\section{Questions:}

1. Which specimen (A or B) had the largest measurement of error, and why?

2. Are the measurements of volume error consistent with the measurements of area error considering the different number of sections?

\section{Drawing Conclusions and Student Assessment}

The data collected on the worksheets are helpful for seeing how to work the problems and the thought process into the concepts presented. The worksheet would also be good for classroom discussion into the various means is estimating area and volume of an object by $2 \mathrm{D}$ slices projected as compared to already knowing the size and shape of an object. Real life examples of a tumor being treated by a new compound and determining if the treatments is working would be an engaging exercise for discussion. 


\section{Appendix B: Assessments}

\section{Pre-Test for Geometric Educational Module}

\section{Questions:}

1. What does the term "stereology" mean?

2. A man is holding a ball in the air as a light source shines on the ball at a horizontal level. What shape do you expect the ball's shadow to form on the wall?

3. A light source is shining on one side of a cube at a horizontal level. What shape will the cube's side take on the wall?

4. What would the image from (3) appear as on the wall? (Draw the image).

5. Suppose one had a tumor in one's lungs that could be detected with a dye that would show up on an X-ray. You have a chance to pin point the tumor before surgery but you only have ability for two X-rays. What two positions would be best to take these $2 \mathrm{X}$-rays? Draw diagrams and explain your answers.

6. Would the angle like structures in block A \& B project the same size area outline on a 2-D plane? Assume the light source is the same distance away from both, directly on the seam (or middle corner) of the angle in both blocks and the structures are of equal dimensions.

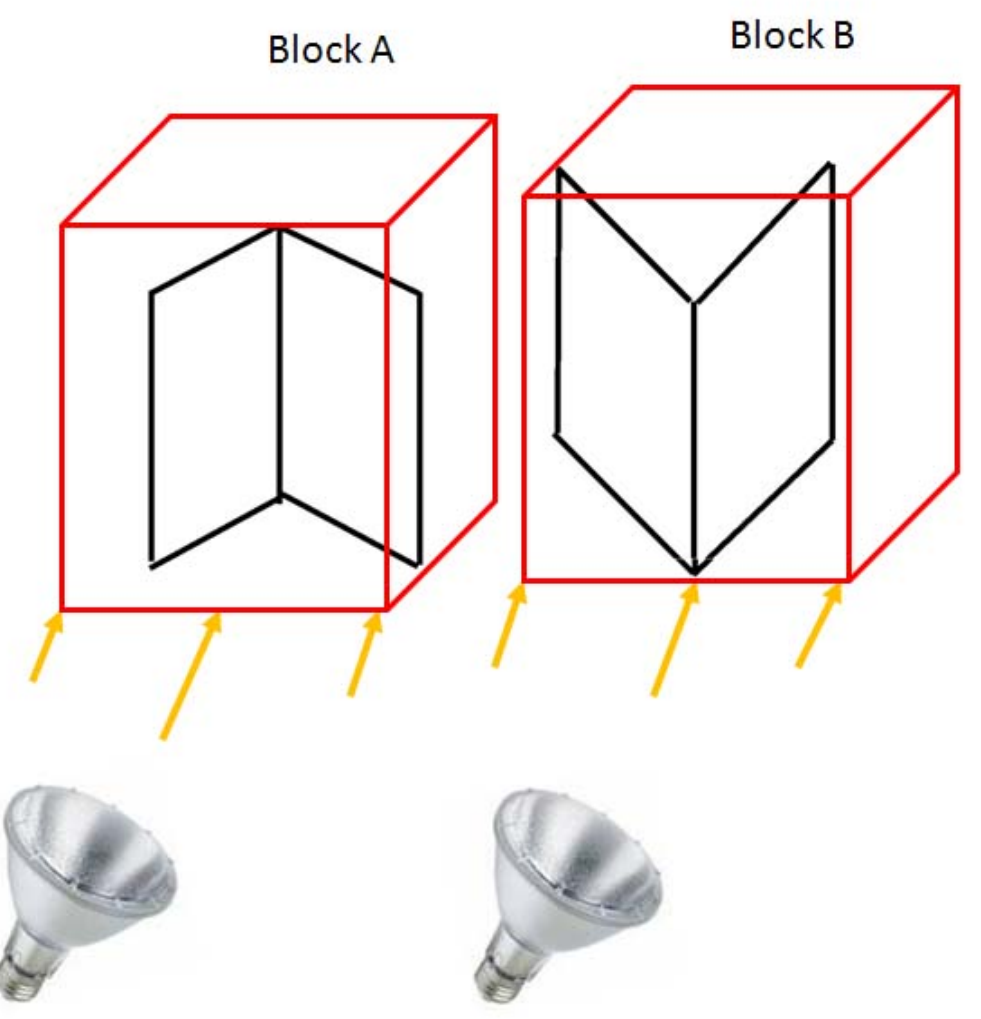

Figure 13. A sample problem used in the pre-/post-test. Students should estimate that a rectangle will be projected on the paper in both cases and would appear the same. 
7. Below light $\mathrm{A}$ is directly facing one side of the box, but light $\mathrm{B}$ is facing the corner of the box, and both are the same distance from the box. The box is $1 \mathrm{~cm}$ on every side. Draw the estimated image projected for light $\mathrm{A}$ and light $\mathrm{B}$ at a horizontal levels. Are the images the same size?

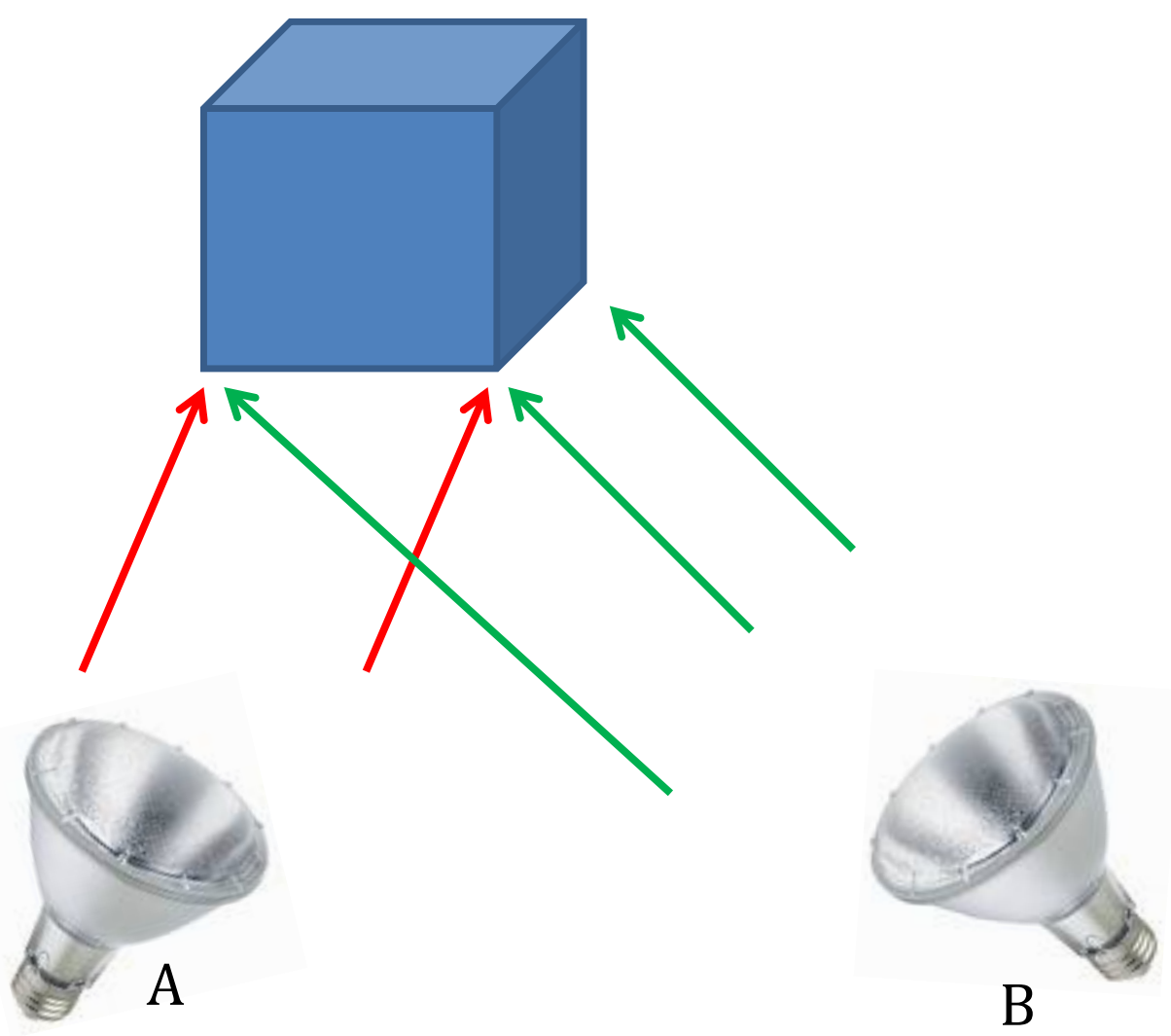

Figure 14. A sample problem used in the pre- /post-test. Students should estimate that a rectangle will be projected on the paper in both cases. In case A, a smaller rectangle will be projected as compared to the projection obtained by $\mathrm{B}$. 


\section{Survey Results}

\section{Pre-test data only}
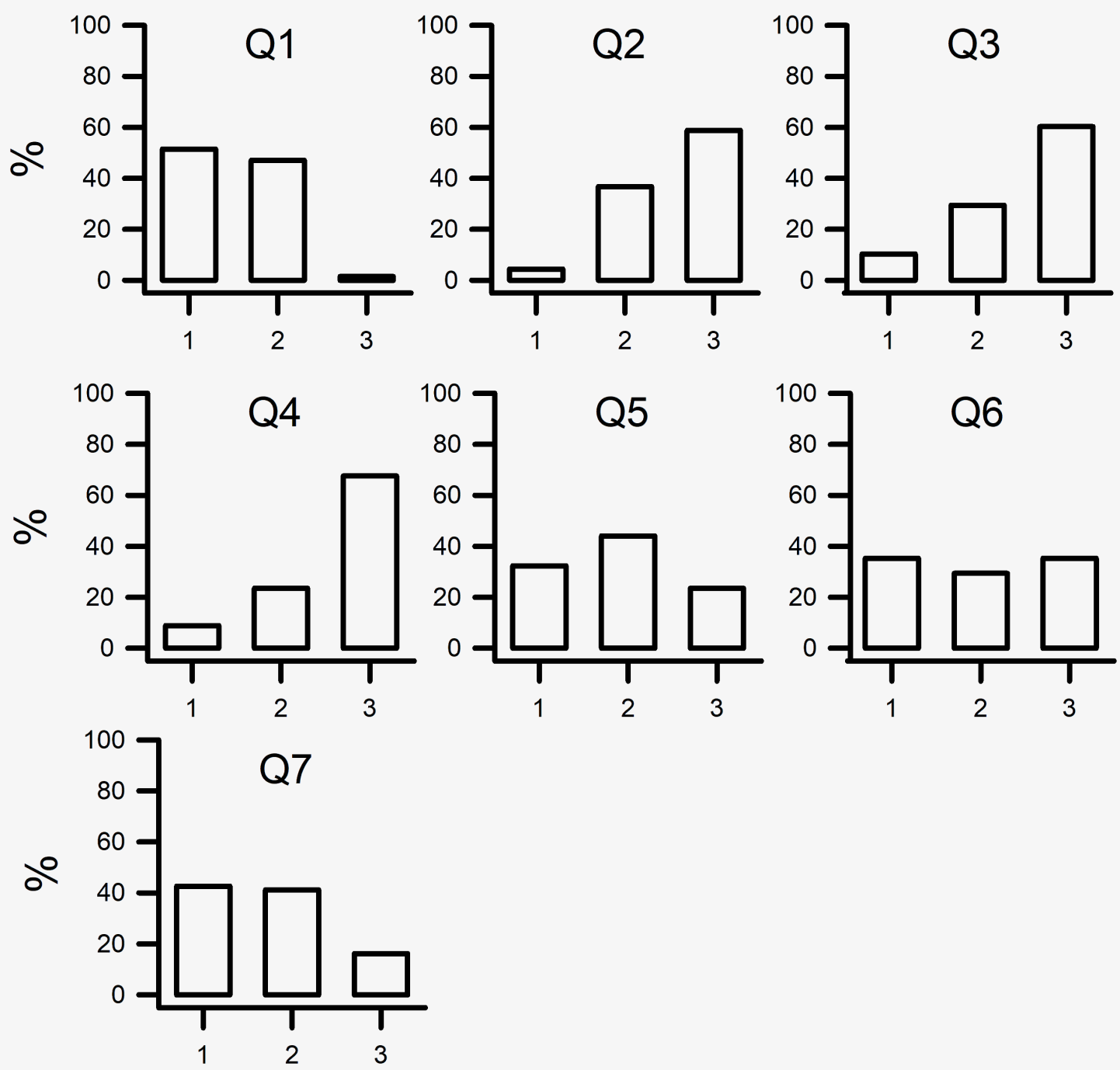

Figure 15. Survey results by no-science students for the pre-test template for questions 1 through 7 . The percent correct are shown on the $\mathrm{Y}$-axis and the rubric score on the $\mathrm{x}$-axis for each qustion .

\section{Rubric for Scoring}

Questions (1-3) follows:

\#1. IDK (I do not know) or a blank or non-sensible

\#2. Something answered but not fully correct. Some misconception

\#3. Correct answer

Sample Answers for Various Questions Are as Follows:

Q1.

Sample of \#2 level: Study of sound, Study of stereos, Study of light, Study of steroids,

Sample of \#3 level: Study of 3-D shapes

Q2. 
Sample of \#2 level: $1 / 2$ of the ball, oval, cone shape, egg shape, semi-circle Sample of \#3 level: Circle

Q3.

Sample of \#2 level: same as cube, triangle, diamond, rhombus

Sample of \#3 level: square

Q4.

Sample of \#2 level: Shapes such as cube, triangle, diamond, rhombus

Sample of \#3 level: Shape square

Q5.

Sample of \#2 level: front \& back, bottom \& front, bottom \& back, 2 sides left \& right

Sample of \#3 level: front \& side

Q6.

Sample of \#2 level: no, no difference, they would look 3-D

Sample of \#3 level: yes, same size; yes, both look at corner but opposite.

Q7.

Sample of \#2 level: yes, odd drawings with one taller than other, squares at different angles but same size

Sample of \#3 level: no, two different sizes with one square and other a rectangle; no as shadows are at different angles 


\section{Mission, Review Process \& Disclaimer}

The Association for Biology Laboratory Education (ABLE) was founded in 1979 to promote information exchange among university and college educators actively concerned with teaching biology in a laboratory setting. The focus of ABLE is to improve the undergraduate biology laboratory experience by promoting the development and dissemination of interesting, innovative, and reliable laboratory exercises. For more information about ABLE, please visit http://www.ableweb.org/。

Advances in Biology Laboratory Education is the peer-reviewed publication of the conference of the Association for Biology Laboratory Education. Published articles and extended abstracts are evaluated and selected by a committee prior to presentation at the conference, peer-reviewed by participants at the conference, and edited by members of the ABLE Editorial Board. Published abstracts are evaluated and selected by a committee prior to presentation at the conference.

\section{Citing This Article}

O’Neil A, Krall RM, Sanden M, Cooper RL. 2020. developing algebraic and geometric understanding of stereology in biological contexts. Article 77 In: McMahon K, editor. Advances in biology laboratory education. Volume 41. Publication of the 41st Conference of the Association for Biology Laboratory Education (ABLE). https://doi.org/10.37590/able.v41.art77

Compilation (C) 2020 by the Association for Biology Laboratory Education, ISBN 1-890444-17-0. All rights reserved. No part of this publication may be reproduced, stored in a retrieval system, or transmitted, in any form or by any means, electronic, mechanical, photocopying, recording, or otherwise, without the prior written permission of the copyright owner.

ABLE strongly encourages individuals to use the exercises in this volume in their teaching program. If this exercise is used solely at one's own institution with no intent for profit, it is excluded from the preceding copyright restriction, unless otherwise noted on the copyright notice of the individual chapter in this volume. Proper credit to this publication must be included in your laboratory outline for each use; a sample citation is given above. 